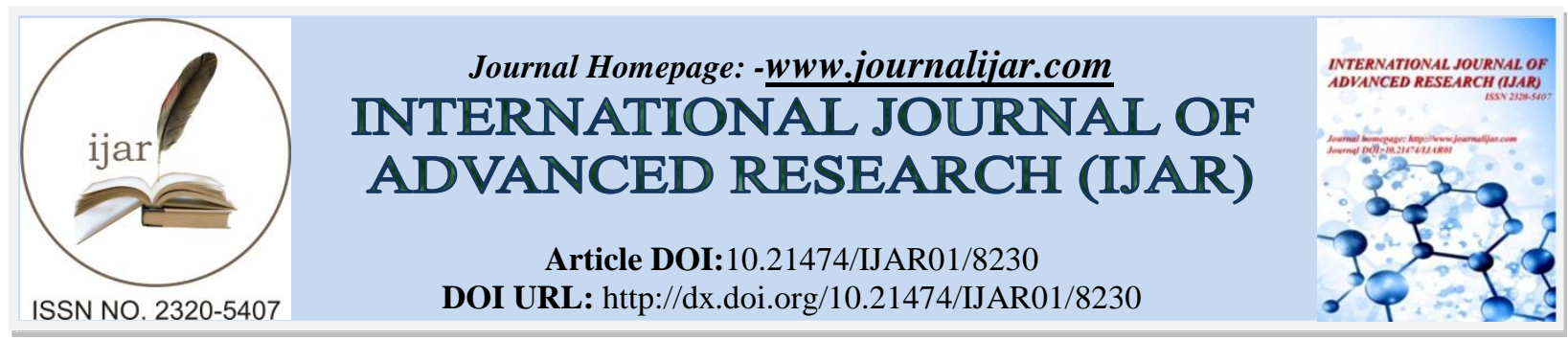

RESEARCH ARTICLE

\title{
FEMALE LITERACY: A SUSTAINABLE DEVELOPMENTAL ISSUE TO MINIMISE INFANT AND MATERNAL MORTALITY IN INDIA.
}

\section{Amrita Pal ${ }^{1}$ and Avik Chattopadhaya ${ }^{2}$.}

1. Lecturer, B. K. Roy Foundation, under PGIHAPanchaSayar, Kolkata, W. Bengal-700 094.

2. Faculty, Department of Commerce (Evening Shift) Seth AnandramJaipuria College, 10, Raja Naba Krishna Street,Sobha Bazar, Kolkata- 700005.

\section{Manuscript Info}

\section{Manuscript History}

Received: 18 October 2018

Final Accepted: 20 November 2018

Published: December 2018

\section{Abstract}

Female literacy has become a crucial issue to fight against infant mortality and maternal mortality in any civilized country for an overall socio-economic development. To ensure a sustainable socio-economic development in India, more initiatives should be taken to eradicate female illiteracy by providing all sorts of educational help to Indian women. This study is conducted to evaluate the state wise rate of female literacy, infant mortality and maternal mortality in India. Another objective of this study is to explore the correlation between female literacy and infant mortality as well as between female literacy and maternal mortality in India. Taking the Census data of Government of India, the analyses have been conducted to reveal how far the different states of India have accomplished satisfactory level of female literacy to minimize both infant and maternal mortality.

Copy Right, IJAR, 2017,. All rights reserved.

\section{Introduction:-}

It is an accepted fact that with a poor or low literacy rate no nation can achieve a sustainable economic growth. In this context, the role of female literacy is also very significant. Developing countries like India always have to face wide discrepancy between male and female literacy rate because of gender imbalances, income imbalances, religious imbalances, caste imbalances and technological barriers prevailing in the country. The school of thought of welfare economics considers that if a woman remains illiterate then the entire family has to bear the consequences of her illiteracy. Even, the country has to suffer from high levels of fertility as well as mortality. Once UNESCO has reported regarding the massive illiteracy of India whereas the census of 2011 shows the male literacy rate in India is about $82.14 \%$ where for female it is about $65.46 \%$. According to the census of 2011 , the growth in female literacy rate $(11.8 \%)$ is very significant and it is increasing faster than the growth rate of male literacy (6.5\%). Moreover, female illiteracy stimulates the mortality rate of our demography and the mortality is one of the prime economic variables of our nation. It has been affecting the population, employment, national income and overall the economic growths of the developing country like India.

Most of the countries in the world, developed as well as developing have experienced radical enhancement in life expectancy. Though since independence both the infant mortality and maternal mortality are becoming the threats to India, the present scenario has been remarkably changed and a rapid decline in both of the mortality rates has improved the situation. Apart from the increase in female literacy, the factors contributing towards improvement in

Corresponding Author:-Amrita Pal.

Address:-Lecturer. B. K. Rov Foundation. under PGIHAPanchaSavar. Kolkata. W. Bengal-700 094. 
this situation are the nation's increased rate in GDP, increase in per-capita income, advancement in quality treatment, improvement in human nutrition, better housing and clothing facilities, improvement in sanitation etc.

Standing on the threshold of sustainable economic development in India, it is the time to estimate how far female literacy is growing to bring that sustainable development and to minimize both infant and maternal mortality.

\section{Literature Update:-}

Several researches have been conducted to establish the type of relationship between female literacy and infant mortality as well as female literacy and maternal mortality in any nation, irrespective of developed or developing. It is a well accepted fact that in both cases, in any country, mortality rate is inversely associated with the female literacy rate. In this context, the status of women's education and under-five children mortality as well as their health inequalities have been studied in selected Sub-Saharan African Countries [1] during the period from 1990 to 2015. This study has been conducted to analyse relationship trends with the help of Logistic regression and Buis's decomposition method. Role of different determinants of mortality in any country, irrespective of developed and developing has been analytically explained by highlighting the factors like public health, urbanization, medical facilities like vaccination etc. [2] This study also finds out that poor infrastructure in health and hygiene services, lack of nutritious foods, lack of sanitation, effect of war and lack of female literacy etc. are the major causes behind infant and maternal mortality. A study has also been carried out to establish how female literacy is related with mortality rates (both infant mortality and maternal mortality) and how the socio-cultural, biological and medical factors influence infant and maternal deaths [3] in a country like India. To explore the trends and factors determining child (under-5) mortality in Bangladesh, a study is successfully undertaken [4]. The study has used data from crosssectional Bangladesh Demographic and Health Surveys (BDHSs). By employing Cox's proportional hazards model to identify the associated factors with under-five mortality, the study finds out the urban-rural disparity in child mortality showing a decreasing trend. The type of relationship between female literacy and maternal mortality rate in the developing countries has been critically studied [5] through longitudinal relationship study in the developing countries from select six regions like East Asia, Central Asia, Africa, Europe, Latin America and South Asia.

\section{Objectives AndMethodology:-}

This study is an attempt to find out the type of relationship between female literacy and maternal mortality as well as between female literacy and infant mortality in Indian context. Considering the growing importance of sustainable economic development in India, this is also an attempt to realise that the growth rate of female literacy in India is in line with that desired sustainable development and to minimize both infant and maternal mortality.

Thus, the objectives include:-

1. To identify the prevailing relationship between female literacy and maternal mortality in India.

2. To identify the prevailing relationship between female literacy and infant mortality in India.

3. To study the present status of female literacy, maternal mortality and infant mortality to understand whether female literacy is growing in a sustainable rate to minimize both maternal mortality and infant mortality in considerable rate in India.

Relevant charts, diagrams are used to show the changes in the rate of female literacy, maternal mortality and infant mortality in India. A correlation analysis is conducted to show the relationship between female literacy and maternal mortality as well as between female literacy and infant mortality in India.

\section{Status Of Female Literacy In India:-}

Table 1:-Female Literacy In Different States In India

\begin{tabular}{|l|c|c|c|c|c|}
\hline \multicolumn{1}{|c|}{ States } & $\mathbf{1 9 8 1}$ & $\mathbf{1 9 9 1}$ & $\mathbf{2 0 0 1}$ & $\mathbf{2 0 1 1}$ & $1981-2011$ \\
\hline Andhra Pradesh & 24.1 & 32.7 & 50.4 & 59.7 & 35.6 \\
\hline Arunachal Pradesh & 14 & 29.7 & 43.5 & 59.5 & 45.5 \\
\hline Bihar & 16.5 & 22.9 & 33.1 & 53.3 & 36.8 \\
\hline Delhi & 62.6 & 67.6 & 74.7 & 80.9 & 18.8 \\
\hline Haryana & 26.9 & 40.5 & 55.7 & 66.7 & 39.8 \\
\hline Karnataka & 33.1 & 44.3 & 56.9 & 68.1 & 35 \\
\hline Kerala & 75.6 & 86.2 & 87.7 & 91.9 & 16.3 \\
\hline Madhya Pradesh & 19 & 28.8 & 50.3 & 60 & 41 \\
\hline
\end{tabular}




\begin{tabular}{|l|c|c|c|c|c|}
\hline Maharashtra & 41 & 52.3 & 67.4 & 75.4 & 34.4 \\
\hline Orissa & 25.1 & 34.7 & 50.5 & 64.3 & 39.2 \\
\hline Punjab & 39.7 & 50.4 & 63.4 & 71.3 & 31.6 \\
\hline Rajasthan & 14 & 20.4 & 43.9 & 52.6 & 38.6 \\
\hline Tamil Nadu & 40 & 51.3 & 64.4 & 73.8 & 33.8 \\
\hline Uttar Pradesh & 17.2 & 25.3 & 42.2 & 59.2 & 42 \\
\hline West Bengal & 36 & 46.5 & 59.6 & 71.1 & 35.1 \\
\hline Goa & 55.1 & 67.1 & 75.4 & 81.8 & 26.7 \\
\hline Gujarat & 38.4 & 48.6 & 57.8 & 70.7 & 32.3 \\
\hline Himachal Pradesh & 37.7 & 52.1 & 67.4 & 76 & 38.3 \\
\hline Manipur & 34.6 & 47.6 & 60.1 & 73.1 & 38.5 \\
\hline Mizoram & 68.6 & 78.6 & 86.7 & 89 & 20.4 \\
\hline Meghalaya & 37.2 & 44.8 & 59.6 & 73.7 & 36.5 \\
\hline Nagaland & 40.4 & 54.7 & 61.5 & 76.6 & 36.2 \\
\hline Sikkim & 27.4 & 46.7 & 60.4 & 76.4 & 49 \\
\hline Tripura & 38 & 49.6 & 64.9 & 83.1 & 45.1 \\
\hline Andaman and Nicobar & 53.2 & 65.5 & 75.2 & 81.8 & 28.6 \\
\hline Chandigarh & 69.3 & 72.3 & 76.5 & 81.3 & 12 \\
\hline Lakshadweep & 55.3 & 72.9 & 80.5 & 88.2 & 32.9 \\
\hline Puducherry & 53 & 65.6 & 73.9 & 81.2 & 28 \\
\hline Source & & &
\end{tabular}

Source :- Curr Pediatric Res 2014 Volume 18 Issue 1

Table 1highlights the status of female literacy in different states of India where changes are figured out for the period of 1981-2011. It is found that the overall rate of female literacy in India has been increased remarkably and it is more than double from 1981 to 2011. In 1981, Arunachal Pradesh, Rajasthan had the lowest literacy rate. Kerala had achieved highest literacy rate in 1981 and currently $91.9 \%$ female are literate in Kerala. It is also found out that among the states of India, Kerala is the best performer in respect of female literacy as per census of 2011. The above table depicts that Arunachal Pradesh, Sikkim, Madhya Pradesh,Uttar Pradesh and Tripura have gained maximum litaracy during 1981-2011.

Fig 1:-State Wise Female Literacy Rate Curves From 1981 To 2011;-

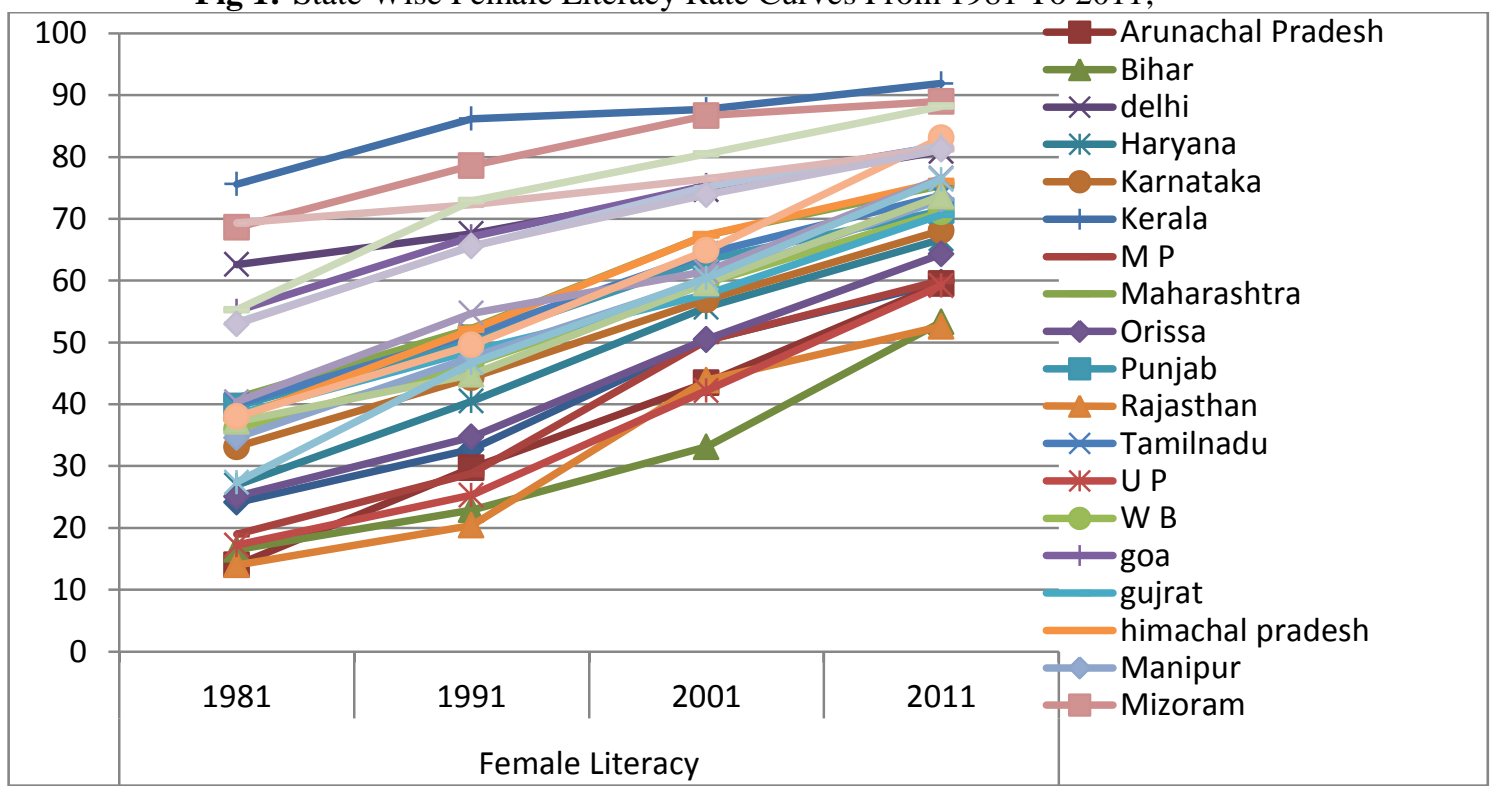

Figure-1 interprets that the female literacy rate curve of Sikkim is steeper than the other states. Sikkim has achieved maximum female literacy gain (49\%) among all other states as per census of 2011. The female literacy rate curve of Delhi and Chandigarh are flatter than the others. They have achieved good percentage of female literacy in 1981 
viz 62.6 and 69.6 but the latter scenario is not remarkably changed. The last female literacy rates of both the states are successively 80.9 and 81.3 percent respectively.

\section{Status Of Maternal And Infant Mortality In India:-}

Maternal mortality is a susceptible symbol of socio-economic development of our community or nation. Maternal mortality is defined by the WORLD HEALTH ORGANISATION (WHO) as "The death of a woman while pregnant or within 42 days of termination of pregnancy, irrespective of the duration and site of the pregnancy, from any cause related to or aggravated by the pregnancy or its management but not from accidental or individual causes."

In 2017 report, the world maternal mortality rate had declined 44\% since 1990, but the picture is still very alarming. In India everyday 830 women die due to pregnancy or child -birth related causes. The common causes of maternal mortality are listed here. Hemorrhages, Infections (usually after child birth), Eclampsia, Unsafe abortion, Child marriage, Lack of access to health care, HIV, Lack of contraceptives, Women treated as inferior in society, Poor sanitation.

According to the census of 2011, the maternal mortality rate in India was about 167 per 1,00,000 live birth. In West Bengal it was about $77.08 \%$, so the percentage is still very alarming. But Govt. has taken some initiatives to reduce this rate. Improvement in literacy rate, establishment of health centers in rural and backward regions, an increase in the use of contraception, awareness for more birth in the hospital, with the presence of skilled personnel are the preventive measures taken by the Govt. for contracting this rate.

Table 2:-Maternal Mortality In Different States In India

\begin{tabular}{|l|c|c|c|c|}
\hline \multicolumn{1}{|c|}{ States } & $\mathbf{2 0 0 4 - 0 6}$ & $\mathbf{2 0 0 7 - 0 9}$ & $\mathbf{2 0 1 0 - 2 0 1 2}$ & $\mathbf{2 0 1 1 - 2 0 1 3}$ \\
\hline Assam & 480 & 390 & 328 & 300 \\
\hline Bihar & 312 & 261 & 219 & 208 \\
\hline Madhya Pradesh & 335 & 269 & 230 & 221 \\
\hline Orissa & 303 & 258 & 235 & 222 \\
\hline Rajasthan & 388 & 318 & 255 & 244 \\
\hline Uttar Pradesh & 440 & 359 & 292 & 285 \\
\hline Andhra Pradesh & 154 & 134 & 110 & 92 \\
\hline Karnataka & 213 & 178 & 144 & 133 \\
\hline Kerala & 95 & 81 & 66 & 61 \\
\hline Tamil Nadu & 111 & 97 & 90 & 79 \\
\hline Gujarat & 160 & 148 & 122 & 112 \\
\hline Haryana & 186 & 153 & 146 & 127 \\
\hline Maharashtra & 130 & 104 & 87 & 68 \\
\hline Punjab & 192 & 172 & 155 & 141 \\
\hline West Bengal & 141 & 145 & 117 & 113 \\
\hline
\end{tabular}

Source: National Institution for Transforming India, Government of India

Table- 2 shows the maternal mortality rate in different states of India from 2004 to 2013. Kerala has the lowest maternal mortality rate in 2011-2013. This state keeps a steady rate in maternal mortality to retain its best position. Though Assam has shown its initially first position in the context of maternal mortality rate keeping the highest rate of 480 per 100000 live birth but it has also drastically improved the rate of maternal mortality from the initial figure to 300 per 100000 live birth in 2013.

Fig 2: State Wise Maternal Mortality Rate Curves From 2004-06 To 2011-13

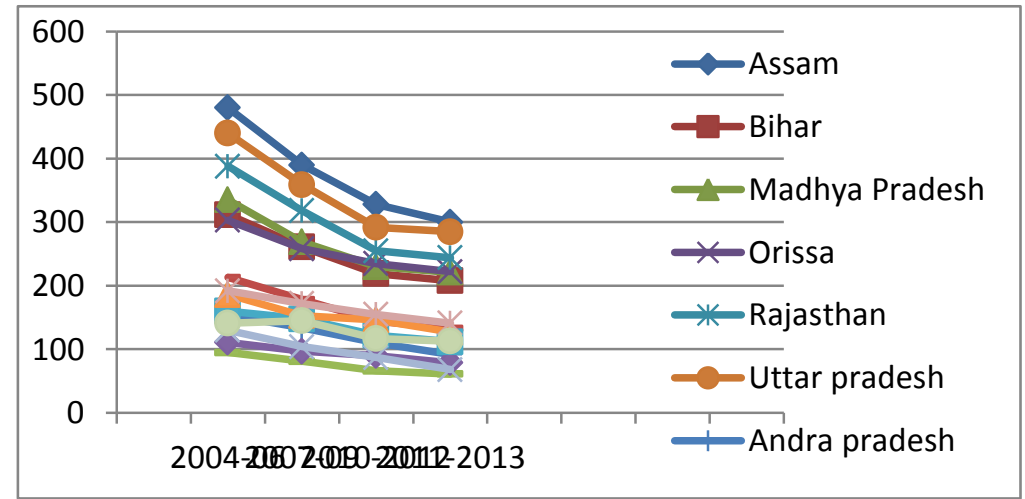


Figure-2 interprets that the maternal mortality rate curve in Kerala is more or less horizontal, there is no radical improvement in maternal mortality rate in Kerala (95-61/100000 live birth). Assam has achieved remarkable fall in maternal mortality rate from 2006 to 2013 and the curve is strongly downward sloping.

On the other hand, the Infant Mortality Rate (IMR) is a crucial indicator of our Indian economic structure. Infant mortality refers to the death of young children typically those whose age is less than one year. The major causes of infant mortality can be listed as problem with brain functions after birth, blood infection, diarrhea, malaria, measles, malnutrition and other syndromes responsible for death.

According to the National Institution for Transforming India (NITI Aayog) in 2016 the IMR was about 34 per 1000 live births in India. The IMR rate has been considerably decreased. Apart from sustainable development in mothers' level of education over the nation, there may be also some major initiatives towards decline in the infant mortality rate like improvement in medical science, access to clean drinking water, proper sanitation, vaccination or immunization for infectious diseases, polio campaign for the awareness of people to eradicate polio and other public measures which can help to reduce infant mortality.

Table 3:-Infant Mortality (Per 1000 Live Births) In Different States In India:-

\begin{tabular}{|c|c|c|c|c|}
\hline States & 1981 & 1991 & 2001 & 2011 \\
\hline Andhra Pradesh & 55 & 49 & 43 & 43 \\
\hline Arunachal Pradesh & 91 & 83 & 61 & 32 \\
\hline Bihar & 75 & 70 & 57 & 44 \\
\hline Delhi & 54 & 49 & 40 & 28 \\
\hline Goa & 51 & 34 & 28 & 11 \\
\hline Gujarat & 78 & 69 & 59 & 41 \\
\hline Haryana & 52 & 55 & 40 & 44 \\
\hline Himachal Pradesh & 82 & 75 & 45 & 38 \\
\hline Karnataka & 74 & 60 & 54 & 35 \\
\hline Kerala & 42 & 37 & 18 & 12 \\
\hline Madhya Pradesh & 133 & 107 & 94 & 59 \\
\hline Maharashtra & 74 & 58 & 49 & 25 \\
\hline Manipur & 28 & 36 & 21 & 11 \\
\hline Meghalaya & 80 & 76 & 58 & 52 \\
\hline Mizoram & 53 & 58 & 41 & 34 \\
\hline Nagaland & 51 & 55 & 39 & 21 \\
\hline Orissa & 125 & 108 & 90 & 57 \\
\hline Punjab & 74 & 54 & 43 & 30 \\
\hline Rajasthan & 87 & 81 & 79 & 52 \\
\hline Sikkim & 60 & 57 & 43 & 27 \\
\hline Tamil Nadu & 54 & 53 & 44 & 22 \\
\hline Tripura & 82 & 78 & 64 & 29 \\
\hline Uttar Pradesh & 99 & 89 & 84 & 57 \\
\hline West Bengal & 62 & 67 & 54 & 32 \\
\hline Andaman \& Nicobar & 69 & 49 & 41 & 23 \\
\hline Chandigarh & 48 & 46 & 44 & 20 \\
\hline Lakshadweep & 91 & 80 & 60 & 24 \\
\hline Puducherry & 34 & 47 & 28 & 19 \\
\hline INDIA & 77 & 74 & 54 & 44 \\
\hline
\end{tabular}

Source: Curr Pediatric Res 2014 Volume 18 Issue 1

Table-3 provides Infant Mortality Rate (IMR) from the four censuses 1981 to 2011. Goa and Manipur have the least IMR in 2011 census whereas Uttar Pradesh, Madhya Pradesh and Orissa had the maximum IMR. In 1981, Madhya 
Pradesh had the maximum IMR, this rate has considerably decreased in 2011 census. IMR in INDIA has improved drastically from 1981 to 2011 . INDIA has gained $42 \%$ reduction in infant mortality during this period.

Fig 3:-State Wise Infant Mortality Rate Curves From 1981 To 2011.

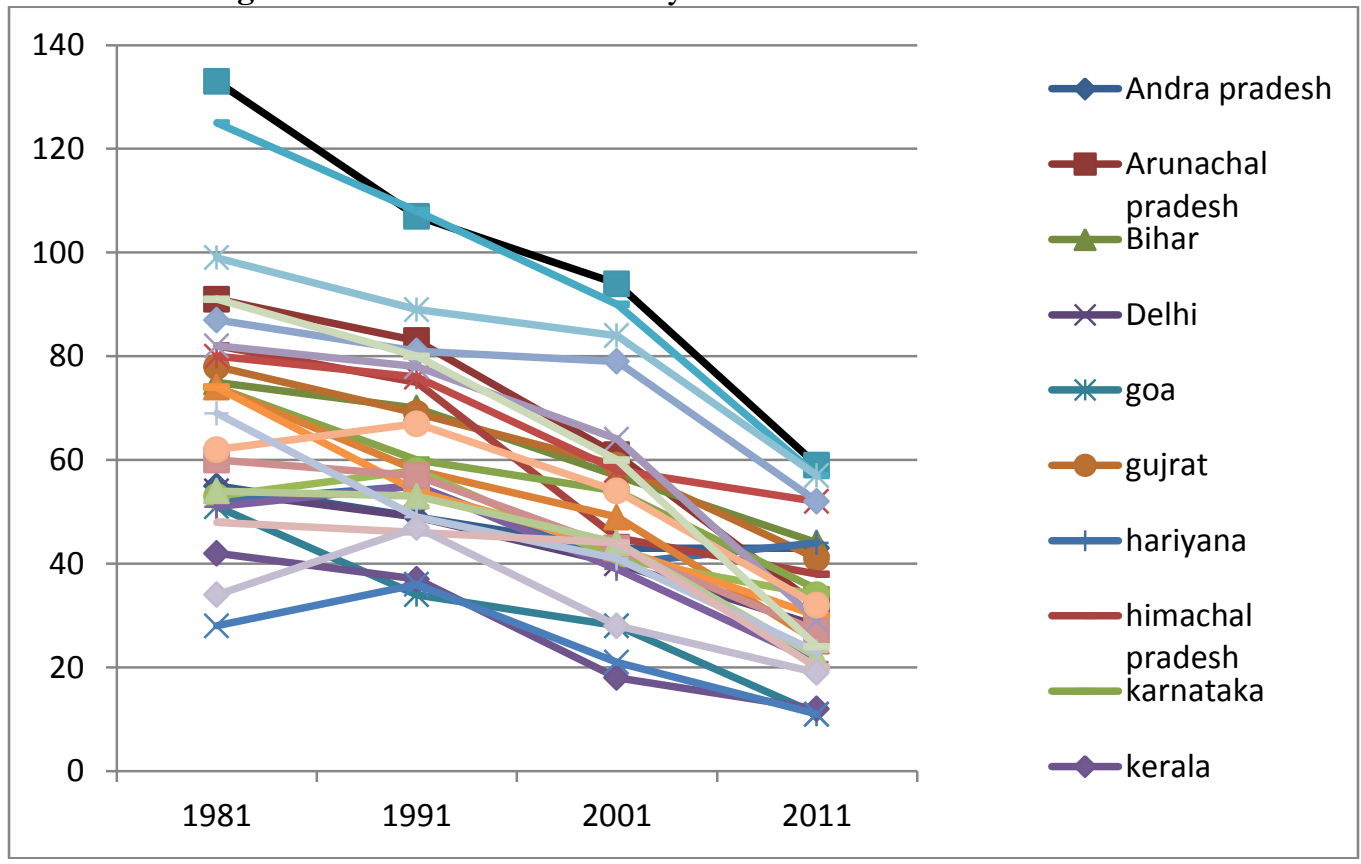

Figure 3 interprets that Goa and Manipur have jointly achieved the best position at the end of 2011 having only the yearly infant mortality of 11 per 1000 live births and following them, Kerala have shown significantly good position having only the yearly infant mortality of 12 per 1000 live births in 2011 census. MadhyaPradesh, throughout the four census periods has shown the maximum IMR which is 59 per 1000 live births in 2011 census.

\section{Relationship Between Female Literacy \& Maternal Mortality And Between Female Literacy \& Infant Mortality In India:-}

The relationship between Female Literacy and Infant Mortality Rate (IMR) as well as between Female Literacy and Maternal Mortality Rate (MMR) are not new to establish. Normally, for any nation, irrespective of developed and developing, there exists inverse relationship between both a) Female Literacy and Infant Mortality Rate (IMR) and b) Female Literacy and Maternal Mortality Rate (MMR).

When and wherever the rate of female literacy increases it leads towards a literate and educated women community. As a consequence, these women do not let their children die in malnutrition or without treatment and Infant Mortality Rate (IMR) automatically falls down. Even literate and educated mothers can take proper care of themselves in time of their pregnancy. As a result, higher rate of female literacy leads towards lower rate of maternal mortality. As recorded in the Census of India in 2001, among all the states and union territories of India, Kerala has the highest female literacy rate (87.9\% of population) and lowest infant mortality rate (16\%). On the contrary, Uttar Pradesh has the low female literacy rate $(43 \%)$ and highest maternal mortality rate. Bihar has the lowest female literacy rate but less IMR than Madhya Pradesh and Orissa, Uttar Pradesh has the highest MMR but more literacy rate (43\%) than Bihar (33\%). There must be a strong correlation between female literacy and IMR as well as female literacy and MMR.The table below follows the female literacy, infant mortality and maternal mortality in different states of the country in the year of 2001. 
Table4:-Relationship Between Female literacy \& Maternal Mortality And Between Female literacy \& Infant Mortality In India

\begin{tabular}{|l|l|l|l|}
\hline States & Female Literacy & IMR** & MMR** \\
\hline India & 54.2 & 71 & 408 \\
\hline Andhra Pradesh & 51.2 & 66 & 154 \\
\hline Assam & 56 & 78 & 401 \\
\hline Bihar & 33.6 & 67 & 451 \\
\hline Gujarat & 58.6 & 64 & 29 \\
\hline Haryana & 56.3 & 69 & 105 \\
\hline Karnataka & 57.5 & 58 & 195 \\
\hline Kerala & 87.9 & 16 & 195 \\
\hline Madhya Pradesh & 50.3 & 97 & 498 \\
\hline Maharashtra & 67.5 & 49 & 135 \\
\hline Orissa & 51 & 98 & 361 \\
\hline Punjab & 63.6 & 54 & 196 \\
\hline Rajasthan & 44.3 & 83 & 677 \\
\hline Tamil Naidu & 64.6 & 53 & 76 \\
\hline Uttar Pradesh & 43 & 85 & 707 \\
\hline West Bengal & 60.2 & 53 & 264 \\
\hline
\end{tabular}

Source: - Census of India, 2001 ** - SRS, Registrar General of India.

The relationship between the IMR with the Female Literacy and the MMR with the Female Literacy are evaluated with the help of Spearman's Rank Correlation Test shown as under-

Table 5:-Spearman's Rank Correlation Test:-

\begin{tabular}{|l|c|c|c|c|c|c|c|c|c|c|}
\hline \multicolumn{1}{|c|}{ States } & $\begin{array}{c}\text { Female } \\
\text { literacy }\end{array}$ & IMR & MMR & $\begin{array}{c}\text { Rank of } \\
\text { female } \\
\text { literacy (x) }\end{array}$ & $\begin{array}{c}\text { Rank } \\
\text { of IMR } \\
(\mathbf{y})\end{array}$ & $\begin{array}{c}\text { Rank of } \\
\mathbf{M M R} \\
\mathbf{( z )}\end{array}$ & $\mathbf{d}_{\mathbf{1}}=\mathbf{x - y}$ & $\mathbf{d}_{\mathbf{2}}=\mathbf{x - z}$ & $\mathbf{d}_{\mathbf{1}}{ }^{2}$ & $\mathbf{d}_{\mathbf{2}}{ }^{2}$ \\
\hline Andhra Pradesh & 51.2 & 6.6 & .154 & 10 & 8 & 11 & 2 & -1 & 4 & 1 \\
\hline Assam & 56 & 7.8 & .401 & 9 & 5 & 5 & 4 & 4 & 16 & 16 \\
\hline Bihar & 33.6 & 6.7 & .451 & 15 & 7 & 4 & 8 & 11 & 64 & 121 \\
\hline Gujarat & 58.6 & 6.4 & .029 & 6 & 9 & 15 & -3 & -9 & 9 & 81 \\
\hline Haryana & 56.3 & 6.9 & .105 & 8 & 6 & 13 & 2 & -5 & 4 & 25 \\
\hline Karnataka & 57.5 & 5.8 & .195 & 7 & 10 & 9.5 & -3 & -2.5 & 9 & 6.25 \\
\hline Kerala & 87.9 & 1.6 & .195 & 1 & 15 & 9.5 & -14 & -8.5 & 156 & 72.25 \\
\hline Madhya Pradesh & 50.3 & 9.7 & .498 & 12 & 2 & 3 & 10 & 9 & 100 & 81 \\
\hline Maharashtra & 67.5 & 4.9 & .135 & 2 & 14 & 12 & -12 & -10 & 144 & 100 \\
\hline Orissa & 51 & 9.8 & .361 & 11 & 1 & 6 & 10 & 5 & 100 & 25 \\
\hline Punjab & 63.6 & 5.4 & .196 & 4 & 11 & 8 & -7 & -4 & 49 & 16 \\
\hline Rajasthan & 44.3 & 8.3 & .677 & 13 & 4 & 2 & 9 & 11 & 81 & 121 \\
\hline Tamil Nadu & 64.6 & 5.3 & .076 & 3 & 12.5 & 14 & 9.5 & -11 & 90.25 & 121 \\
\hline Uttar Pradesh & 43 & 8.5 & .707 & 14 & 3 & 1 & 11 & 13 & 121 & 169 \\
\hline West Bengal & 60.2 & 5.3 & .264 & 5 & 12.5 & 7 & -7.5 & -2 & 56.25 & 4 \\
\hline & ------- & ----- & ----- & ------ & ----- & ----- & ------ & ----- & $\Sigma d_{1}{ }^{2}=$ & $\Sigma d^{2}=$ \\
& & & & & & & & & 1003.5 & 959.5 \\
\hline
\end{tabular}

In the above table the MMR and IMR rate are converted into percentage.

In the four series together, there are two ties in all.

Firstly while getting the relationship between female literacy and maternal mortality it is found that there is one tie involving two states, Tamil Nadu and West Bengal. 


$\begin{aligned} & \text { By Spearman's Rank Correlation Coefficient, it is found that, } \mathrm{r}=1-6\left(\sum \mathrm{d}_{2}{ }^{2}+\Sigma\left(\mathrm{t}^{3}-\mathrm{t}\right) / 12\right) / \mathrm{n}^{3}-\mathrm{n} \\ &=1-6 * 960 / 15^{3}-15 \\ &=1-(5760 / 3360) \\ &=1-1 \cdot 71 \\ &=-0 \cdot 71\end{aligned}$

It is proved from the calculation that there is a strong negative relationship between female literacy and maternal mortality. The correlation coefficient between them is negative (the value of $r$ lies between -1 and +1 ).

Secondly, while getting the relationship between female literacy and infant mortality it is found that there is one tie involving two states, Karnataka and Kerala.

By Spearman's Rank Correlation Coefficient, it is found that, $=1-6\left(\Sigma \mathrm{d}_{1}{ }^{2}+\Sigma\left(\mathrm{t}^{3}-\mathrm{t}\right) / 12\right) / \mathrm{n}^{3}-\mathrm{n}$

$$
\begin{aligned}
& =1-6 *(1004 / 3360) \\
& =-0 \cdot 79
\end{aligned}
$$

It is also proved that there exists a strong negative relation between female literacy and infant mortality.

It is clear from the statistical investigation that it establishes a negative correlation between Female literacy and IMR and also Female literacy and MMR.

\section{Conclusion and Recommendation:-}

This study is an attempt to determine the relationship between female literacy and infant mortality as well as female literacy and maternal mortality. The study reveals that improvement in female literacy results in a decline in infant mortality and maternal mortality. There exists a strong negative correlation between women literacy and infant mortality as well as women literacy and maternal mortality. From the past four censuses (1981-2011) it has been evidenced that female literacy programmes depress the maternal mortality and infant mortality not only in short run but also have long run effect in India. From the inferential statistics it is found that improvement in women literacy is associated with decrease in maternal mortality and infant mortality. Apart from female literacy there are also some socio-economic as well as biological factors that influence both infant and maternal mortality rate. In country like India, the rate of infant mortality and maternal mortality are still alarming. It is high time for the society to take up the problem as a challenge. So it is highly recommended for the Govt. and non Govt. organizations that they should take positive steps to arrange more female literacy programmes in a revolutionary manner to minimize both infant and maternal mortality in India as it is a fact that women education is the key to sustainable development in India.

\section{References:-}

1. Bado, A. R. and Susuman, A. S. (2016): Women's Education and Health Inequalities in Under-Five Mortality in Selected Sub-Saharan African Countries, 1990-2015. Plos One., 11(7): 1-18.

2. Cutler, D., Deaton, A., and Lleras-Muney, A. (2006): The Determinants of Mortality., Journal of Economic Perspectives., 20(3): 97-120.

3. Jain, G. and Bisen, V. (2012): Female Literacy \& Its Relevance with Maternal and Infant Mortality Rates., International Journal of Management (IJM)., 3(2): 65-79.

4. Khan, J. R. and Awan, N. (2017): A Comprehensive Analysis on Child Mortality and Its Determinants in Bangladesh Using Frailty Models.,Archives of Public Health: Bio Med Central., 75:58: 1-10.

5. Pillai, V. K., Maleku, A. and Wei, F. H. (2013): Maternal Mortality and Female Literacy Rates in Developing Countries during 1970-2000: A Latent Growth Curve Analysis., International Journal of Population Research: Hindawi Publishing Corporation., 2013 (163292): 1-11. 